\title{
BMJ Open Changes to cardiovascular risk factors over 7 years: a prospective cohort study of in situ urbanised residents in the Chaoyang District of Beijing
}

\author{
Zhe Li (D) , ${ }^{1,2}$ Shicheng Yu, ${ }^{1}$ Xiaoyan Han, ${ }^{2}$ Jianjun Liu, ${ }^{3}$ Hongyan Yao ${ }^{1}$
}

To cite: Li Z, Yu S, Han X, et al. Changes to cardiovascular risk factors over 7 years: a prospective cohort study of in situ urbanised residents in the Chaoyang District of Beijing. BMJ Open 2020;10:e033548. doi:10.1136/ bmjopen-2019-033548

- Prepublication history for this paper is available online. To view these files, please visit the journal online (http://dx.doi. org/10.1136/bmjopen-2019033548).

Received 09 August 2019 Revised 24 December 2019 Accepted 12 February 2020

Check for updates

(c) Author(s) (or their employer(s)) 2020. Re-use permitted under CC BY-NC. No commercial re-use. See rights and permissions. Published by BMJ.

${ }^{1}$ Office for Epidemiology, Chinese Center for Disease Control and Prevention, Beijing, China

${ }^{2}$ Department for Chronic and Noncommunicable Disease Control and Prevention, Chaoyang District Center for Disease Control and Prevention, Beijing, China

${ }^{3}$ Chinese Center for Disease Control and Prevention, Beijing, China

Correspondence to

Hongyan Yao;

yaohy@chinacdc.cn

\section{ABSTRACT}

Objectives To examine changes in cardiovascular risk factors of in situ urbanised residents between 2010 and 2017.

Design Population-based cohort study.

Setting The Chaoyang District of Beijing, China.

Participants A total of 942 in situ urbanised rural residents aged 35-64 who participated in the cardiovascular disease (CVD) risk factors study in China between 2010 and 2017

Main outcome measures Lifestyles (smoking, drinking and effective exercise) and medical history (diabetes, hypertension, dyslipidaemia, overweight and obesity) were self-reported. New cases of diabetes, hypertension, dyslipidaemia, overweight and obesity were confirmed by physical examination or blood biochemical tests. Multiple linear regression and log-binomial models analyses adjusted for sociodemographic confounders were conducted to evaluate any changes of clinical indexes and to estimate prevalence rate ratios (PRRs), respectively. Results During the study period of 2010-2017, diastolic blood pressure elevated by $3.55 \mathrm{~mm} \mathrm{Hg}$, central blood pressure increased by $4.39 \mathrm{~mm} \mathrm{Hg}$, total cholesterol decreased by $0.29 \mathrm{mmol} / \mathrm{L}$ and hypertension increased significantly ( $P R R=1.25, p<0.05)$ after adjusting for demographic, lifestyle and family history factors. Effective exercise rate ( $\mathrm{PRR}=1.57$ ), prevalence of diabetes $(\mathrm{PRR}=1.36)$ and dyslipidaemia $(\mathrm{PRR}=1.19)$ all increased from 2010 to 2017. However, these changes were not significant after adjusting for confounders $(p>0.05)$. Prevalence of smoking, drinking, hypertension, overweight and obesity was significantly higher in males than females in both 2010 and 2017. In 2017, the 10-year risk of atherosclerotic CVD increased in $29.8 \%$ of participants and decreased in $6.1 \%$ of individuals.

Conclusions CVD risk factors augmented remarkably for in situ urbanised rural residents aged 35-64 in the Chaoyang District of Beijing, especially those indicators related to blood pressure. Awareness of the direction and magnitude of these risk factor changes may be beneficial in informing targeted strategies for preventing CVDs of in situ urbanised populations.

\section{INTRODUCTION}

Over the past three decades, China has experienced the largest acceleration of urbanisation
Strengths and limitations of this study

This is a rare study which uses reliable clinical data to explore the changes in cardiovascular health risks in an in situ urbanised population.

- The longitudinal study design and use of standard protocols and instruments, data collection by trained interviewers, a vigorous quality control throughout the survey period as well as the rigorous statistical methods all enhance the reliability of the findings.

- The study cannot determine a causal relationship between in situ urbanisation and changes in cardiovascular risk factors since there is no control population.

- The information on lifestyles, medical history, family history and income were based on self-report, which may be subject to reporting bias and recall bias.

- As data from six participants with risk factors who died during the study period were not included in the analysis, the final results may be underestimated.

worldwide. China's proportion of urban population increased from $25.8 \%$ in 1990 to $59.6 \%$ in $2018 .{ }^{1}$ It is estimated that one billion people will live in urban areas in China by $2030{ }^{2}$ This urbanisation has emerged from two processes: migration from rural to urban areas and in situ urbanisation of rural areas. ${ }^{3-5}$ In addition to the social and economic alterations of the past few decades, China has experienced an epidemiological transition from predominantly infectious diseases to chronic non-communicable diseases, such as cardiovascular disease (CVD). The disease burden caused by CVD is a serious public health problem in China. ${ }^{6} 7$ It is suggested that this growing disease burden is driven by social macro factors ${ }^{8} 9$ such as urbanisation and ageing. Previous studies into the impact of urbanisation on health have focused on the health of migrants from rural to urban areas, but rarely on that of in situ urbanised rural residents. This is also true for risk factors associated with CVD. Therefore, research on 
changes in CVD risk factors following the tracking of the health indicators for each in situ urbanised resident in China is needed. ${ }^{10-12}$

In 2008, Beijing launched an unprecedented urbanisation project which involved the demolition and transformation of the urban-rural fringe area. ${ }^{13}$ The project involved nine districts, 108 villages and approximately $117 \mathrm{~km}^{2}$. The intention was to demolish all old villages in 2-3years. Chaoyang District is the largest urban area in Beijing, with a permanent population of 3.6 million. By the end of 2013, 102000 households and 208000 rural residents in the district's urban-rural fringe area moved into new high-rise residential communities, thus undergoing in situ urbanisation. Not only were living conditions improved, but income increased due to compensation, while considerable changes were made to lifestyles, such as the use of central heating instead of coal. Most residents were no longer engaged in agricultural work but instead relied on renting to make a profit, since the location of the capital increased housing values. Previously, villagers socialised by playing mahjong and drinking. However, to improve health literacy and enrich the cultural life of the residents who moved back, Chaoyang launched the 'citizenisation' of farmers project, which comprised fitness training courses, disease prevention, flower arrangement and handwork.

These changes in lifestyle and behaviour may effect CVD risk factors including hypertension diabetes, dyslipidaemia, obesity and physical activity. Previous studies confirmed that urbanisation is a double-edged sword for health. ${ }^{349-15}$ Urbanisation offers health benefits including access to services and education, higher incomes and living conditions. However, it also poses risks, such as pollution, transition to Western-style diets and sedentary lifestyles.

So what are the changes and characteristics in CVD risks during in situ urbanisation? This report expands the literature by using longitudinal data from 2010 to 2017 to depict changes and characteristics in CVD risks factors of in situ urbanised rural residents aged 35-64 in the Chaoyang District of Beijing.

\section{MATERIALS AND METHODS}

\section{Study design and participants}

Hongbo community in the Chaoyang District is located in the southeast of Beijing. It is a high-rise building community designed by Xiaohongmen Township in Chaoyang district for local land requisitioning and returning rural residents. Since 2002, the community has developed six subcommunities, of which area $\mathrm{C}$ was the first to be completed, in 2009. From January to June 2010, the first group of returning rural residents from the Xiaohongmen Township moved back to area $\mathrm{C}$ of the community, which was $2 \mathrm{~km}$ away from the original residence.

In 2010, China's national centre for CVD initiated a nationwide, multicentre study of cardiovascular risk factors for the middle-aged and elderly population. The
Xiaohongmen Township in Chaoyang District was a unique area for focusing on an urbanised population in this study. We used a cluster sampling method to select five out of nine buildings, the highest of which had 28 floors, in area C. We then surveyed 1000 returning residents aged 35-64 in July 2010. The detailed methods of this baseline survey have been described previously. ${ }^{16} \mathrm{~A}$ total of $942(94.2 \%)$ residents provided complete baseline information in 2010. Of the 942 participants, 59 (6.3\%) refused to participate in the follow-up study, $87(9.2 \%)$ could not be contacted, 6 (0.6\%) died before 2017, 790 (83.9\%) participated in the follow-up survey (2017), 131 $(13.9 \%)$ were excluded as they did not provide a blood specimen and attend a physical examination, and 19 $(2.0 \%)$ were beyond the age range of the analysis. This resulted in a final sample of $640(67.9 \%)$ participants who had provided complete data both at baseline and follow-up.

\section{Data collection}

The survey was conducted according to the unified implementation plan. Participants' demographic and clinical information, family history and lifestyles were collected by trained interviewers using internationally standardised methods. ${ }^{17}{ }^{18}$ Written informed consent was obtained from each participant prior to data collection.

\section{Physical examinations and blood specimens}

Brachial blood pressure (BP) and central $\mathrm{BP}(\mathrm{CBP})$ were measured three times using a conventional mercury sphygmomanometer and the BPro device with A-Pulse CASP software (Health STATS, Singapore) after each participant rested for $5 \mathrm{~min}$. The BPro device with A-Pulse CASP software showed an accurate agreement in CBP compared with invasively measured CBP. ${ }^{19}{ }^{20}$ The mean of the three measurements was used for analysis. Height was measured to the nearest $0.5 \mathrm{~cm}$ without shoes, using a standard right-angle device and a fixed measurement tape. Body weight without heavy clothes, percentage body fat (PBF) and Visceral Fat Index (VFI) were measured using an Omron body fat and weight measurement device (V-body HbF-359, Omron, Kyoto, Japan). Methods of blood collection and testing have been described previously. ${ }^{16}$ Biochemical indexes involve total cholesterol (TC), triglyceride (TG), low-density lipoprotein cholesterol (LDL-C), high-density lipoprotein cholesterol (HDL-C) and fasting plasma glucose (FPG).

\section{Definitions}

Hypertension was defined as a mean systolic BP $\geq 140 \mathrm{~mm} \mathrm{Hg}$ or a mean diastolic BP $\geq 90 \mathrm{~mm} \mathrm{Hg}$ or selfreported history of hypertension. Diabetes was defined as a fasting plasma glucose level of at least $7.0 \mathrm{mmol} / \mathrm{L}$ or self-reported diabetic history. Dyslipidaemia was defined according to the following measurements: TC $\geq 6.22 \mathrm{mmol} / \mathrm{L}, \mathrm{TG} \geq 2.26 \mathrm{mmol} / \mathrm{L}, \mathrm{HDL}-\mathrm{C}<1.04 \mathrm{mmo} / \mathrm{L}$ or LDL-C $\geq 4.14 \mathrm{mmol} / \mathrm{L}$. Body mass index (BMI: $\mathrm{kg} / \mathrm{m}^{2}$ ) 
Table 1 General characteristics of participants in 2010 and 2017

Characteristics

$2010(n=942)$

$2017(n=640)$

$P$ value

Demographic characteristics

Sex, n (\%)

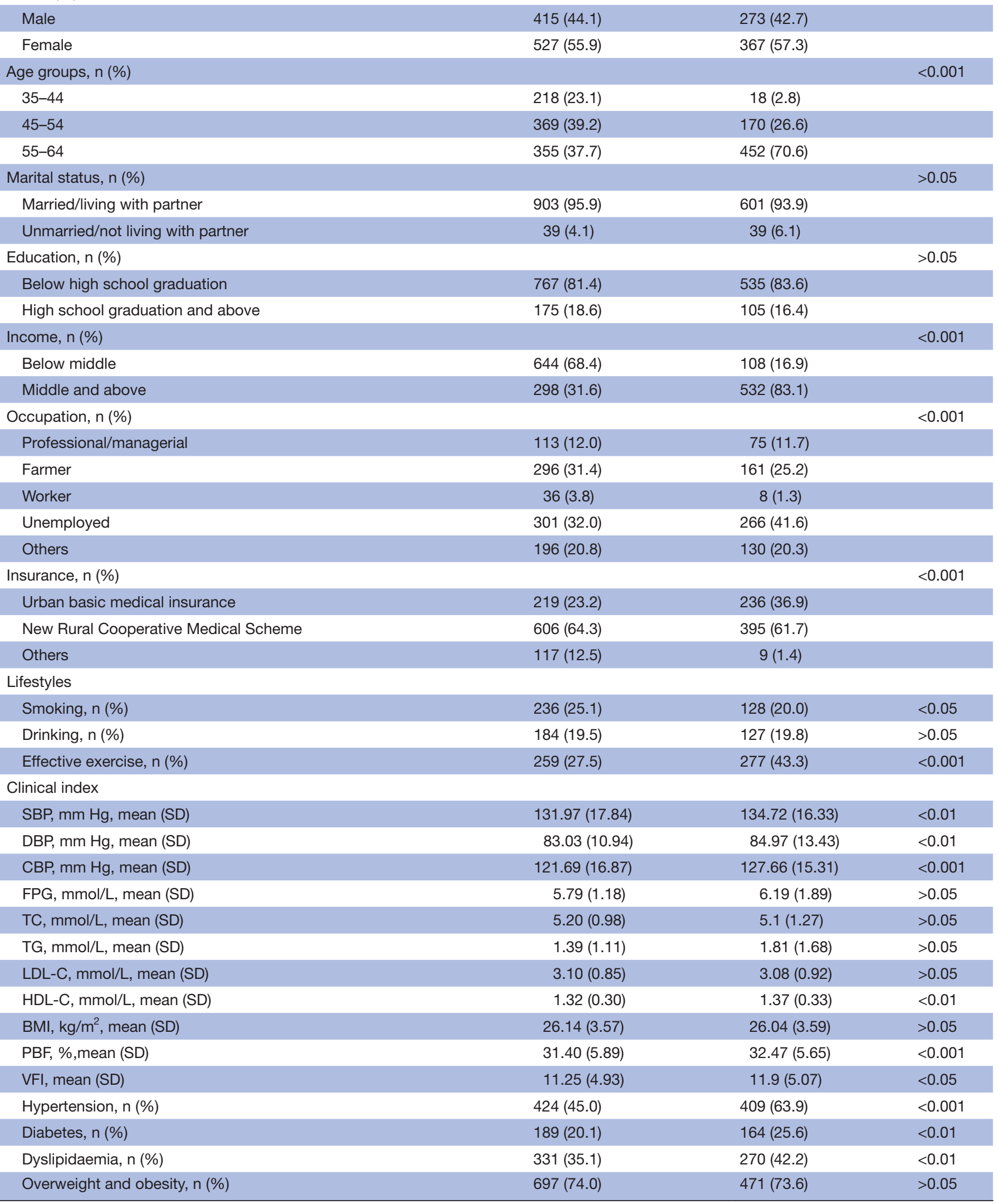




\begin{tabular}{|c|c|c|c|}
\hline Characteristics & $2010(n=942)$ & $2017(n=640)$ & $P$ value \\
\hline \multicolumn{4}{|l|}{ Family history } \\
\hline Family history of hypertension, $\mathrm{n}(\%)$ & $476(50.5)$ & $330(51.6)$ & $>0.05$ \\
\hline Family history of dyslipidaemia, n (\%) & $119(12.6)$ & 79 (12.3) & $>0.05$ \\
\hline Family history of diabetes, $\mathrm{n}(\%)$ & $184(19.5)$ & $126(19.7)$ & $>0.05$ \\
\hline
\end{tabular}

BMI, body mass index; CBP, central blood pressure; DBP, diastolic blood pressure; FPG, fasting plasma glucose; HDL-C, high-density lipoprotein cholesterol; LDL-C, low density lipoprotein cholesterol; PBF, percentage body fat; SBP, systolic blood pressure; TC, total cholesterol; TG, triglyceride; $\mathrm{VFI}$, visceral fat index.

was categorised according to Chinese-specific criteria (overweight: $\geq 24$ and $<28 \mathrm{~kg} / \mathrm{m}^{2}$; obesity: $\geq 28 \mathrm{~kg} / \mathrm{m}^{2}$ ). ${ }^{21}$

Smoking was defined as the use of at least 20 packets of cigarettes or $0.5 \mathrm{~kg}$ leaf tobacco in participants' lifetime or smoking at least one cigarette per day at least for 1 year. Drinking was defined as drinking alcohol once a week. Effective exercise was defined as leisure-time exercise of at least 30 min per day, 5 days a week. Family history of hypertension, dyslipidaemia or diabetes was defined as with the following condition : First-degree relatives (parents, children, brothers or sisters) were definitely diagnosed with hypertension, dyslipidaemia or diabetes.

\section{Statistical analysis}

Descriptive analysis was undertaken to summarise demographic characteristics, lifestyle, clinical information and history of family illness. Variables were described according to their nature, using means (SD), frequency (percentages) or percentages $(95 \% \mathrm{CI})$ for each subgroup. Differences in continuous variables were analysed using t-test, and prevalence values for categorical variables were compared using $\chi^{2}$ test. Multiple linear regression analyses adjusted for sex, age group, marital status, education, income, occupation, insurance, lifestyle and family history were conducted to evaluate any changes to clinical indexes. Log-binomial models, adjusted for the variables mentioned above, were used to estimate prevalence rate ratios (PRRs). ${ }^{22} 23$ Overall risk was assessed based on the 10-year risk assessment method for atherosclerotic CVD (ASCVD), following the 2017 Chinese guidelines for CVD prevention. ${ }^{24}$ As an additional analysis, we compared the main baseline characteristics of the samples not included $(n=302)$ and included $(n=640)$ in the final analysis. All tests of significance were two tailed and $p$ values of $<0.05$ were regarded as significant. Analyses were carried out using SAS V.9.3.

\section{Patient and public involvement}

Patients were not involved in setting the research questions, the design, outcome measures or implementation of the study. They were not asked to advise on interpretation or writing up of results. No patients were advised on dissemination of the study or its main results.

\section{RESULTS}

\section{Sociodemographic, lifestyles and clinical characteristics}

Table 1 shows that the proportion of women was higher than men both in 2010 and 2017. The proportion of residents aged 55-64 increased from $37.7 \%$ to $70.6 \%$. Participants who married or were living with partner made up the majority of the group. Less than $20 \%$ of residents had a high school degree or above. Farmers, workers and the unemployed accounted for nearly two-thirds of this population. More than $60 \%$ were enrolled in the New Rural Cooperative Medical Scheme. The proportion of those with medium or greater levels of income rose from $31.6 \%$ in 2010 to $83.1 \%$ in $2017(\mathrm{p}<0.001)$. Smoking rates in 2017 were lower than in $2010(\mathrm{p}<0.05)$. Effective exercise rate and prevalence of hypertension, diabetes and dyslipidaemia were higher than in $2010(\mathrm{p}<0.01)$, but there were no significant changes to overweight, obesity or drinking rates $(p>0.05)$. Differences in other clinical data or family history between 2010 and 2017 are also shown in table 1 .

\section{Prevalence of risk factors in different demographic groups}

Detailed statistics relating to the prevalence of risk factors in different demographic groups are displayed in table 2. Overall, smoking rates among those with different demographic characteristics declined after 7 years. Drinking rates increased in the following populations: males; those aged 45-54; those who were married or living with partner; those receiving middle income and above; farmers; the unemployed and those with urban basic medical insurance. Effective exercise rates rose in all demographic characteristic subgroups. The prevalence of hypertension, diabetes and dyslipidaemia went up in all the subgroups aside from those who were unmarried/not living with partner and those with below middle income. Overweight and obesity rates showed a downward trend among females, the 45-64 age group, those of different marital statuses and education levels, farmers, people with below middle income and those who were enrolled in the New Rural Cooperative Medical Scheme. The differences in prevalence between subgroups of each sociodemographic feature are also shown in table 2. It is worth mentioning that both in 2010 and 2017, smoking, drinking, hypertension, and overweight and obesity rates were significantly higher in males than females $(p<0.05)$. 


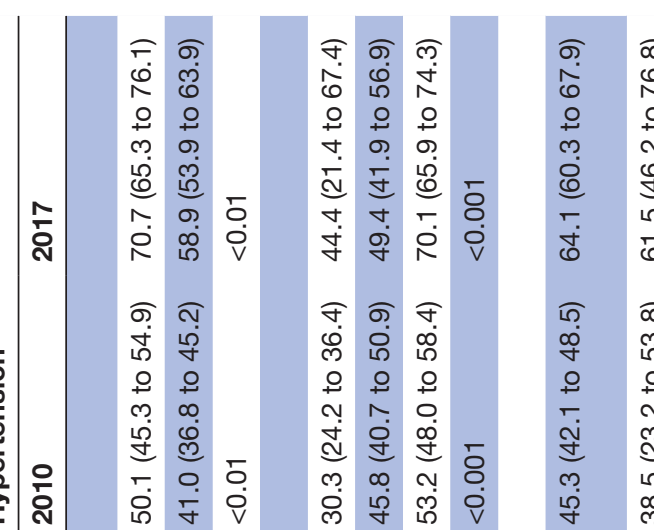

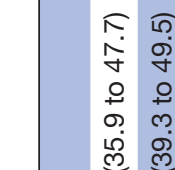

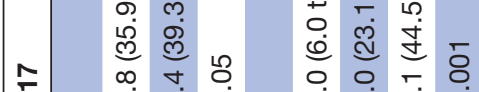

กั่

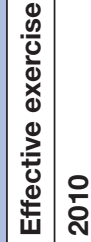

$\widetilde{F}$

लं वं

우

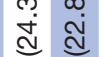

$\begin{array}{lll}\mathbb{1} & \mathbb{N} & 0 \\ & 0 & 0 \\ \infty & 0 & 0 \\ 0 & 0 & 0\end{array}$

ลे

ธิ ब.

ผู่ సं

아오 우

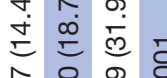

官

ब़ุ

\begin{tabular}{ll}
9 & 0 \\
9 & 0 \\
$\circ$ & 0 \\
\hline & 0
\end{tabular}

co

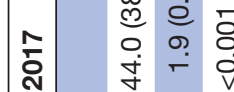

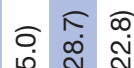

m

웅

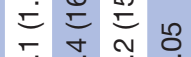

ז

ז.

㑏

일

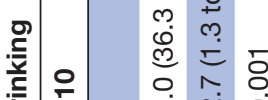

ธก โก

กิ ลิ่

운요

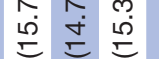

ปั

ন

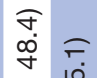

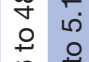

0 운

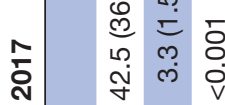

бำ

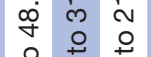

年

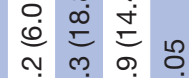

กั

ชิ ฮุ

लं

ธุ่

ำ

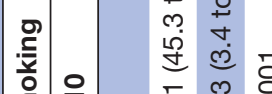

ㅇํำ

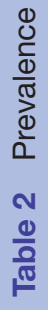

$\stackrel{2}{+}+\frac{1}{\circ}+$

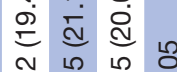

ก)

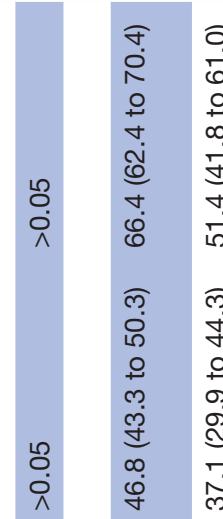

อิ

ถิ

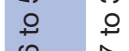

过 㐫

ก)

i में

F.

लें సे

요 웅

点

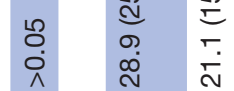

웅

옹

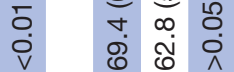

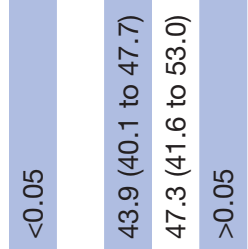

¿.

ஜ

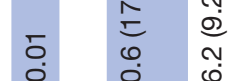

จ

i

$\stackrel{\circ}{\circ}$

ग

㐫

잉

$\begin{array}{ll}\infty & \infty \\ & 0 \\ & 0\end{array}$

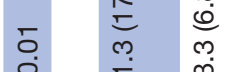

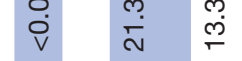

옹

ヘ

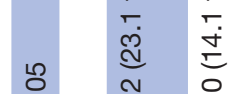

ำ
ले ल

ชุ ซ্

우요

ڤ્山

ले

लें ๆें

สุ กุ

$\stackrel{\infty}{N} \hat{m}$

우우

స̃

का व

ผें ले

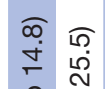

요 운

लं

m $\stackrel{\infty}{=}$

$\rightarrow$ ก

กิ

웅

100

棺

ำ

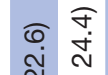

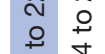

我

$\infty$ 등

ल)

N

ก.

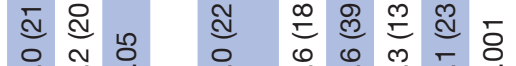

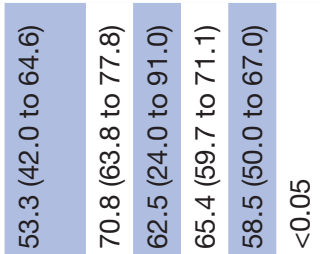

ฮุ

岇

웅 웅ㅇㅇㅇㅇ 우

ळ)

बे वे ल ल ल

م.

-

की ळ

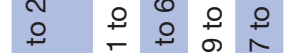

œ

m

․ ल

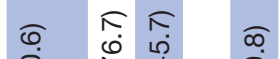

$\begin{array}{llll}0 & 0 & 0 \\ 0 & 0 & 0 & 0 \\ 0 & 0 & 0 & 0 \\ 0 & 0 & 0\end{array}$

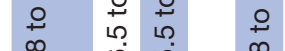

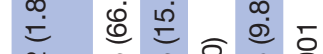

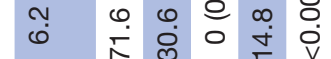

กิ ซ

m N

웅요

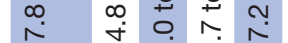

每

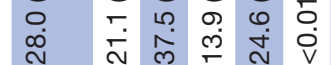

० ब

ले लें

잉

赵

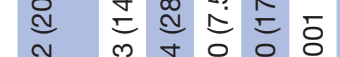

बूं

岗

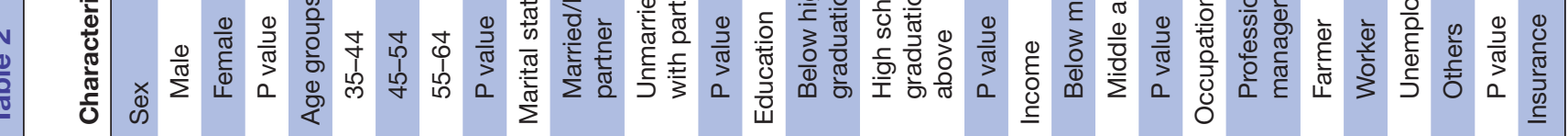




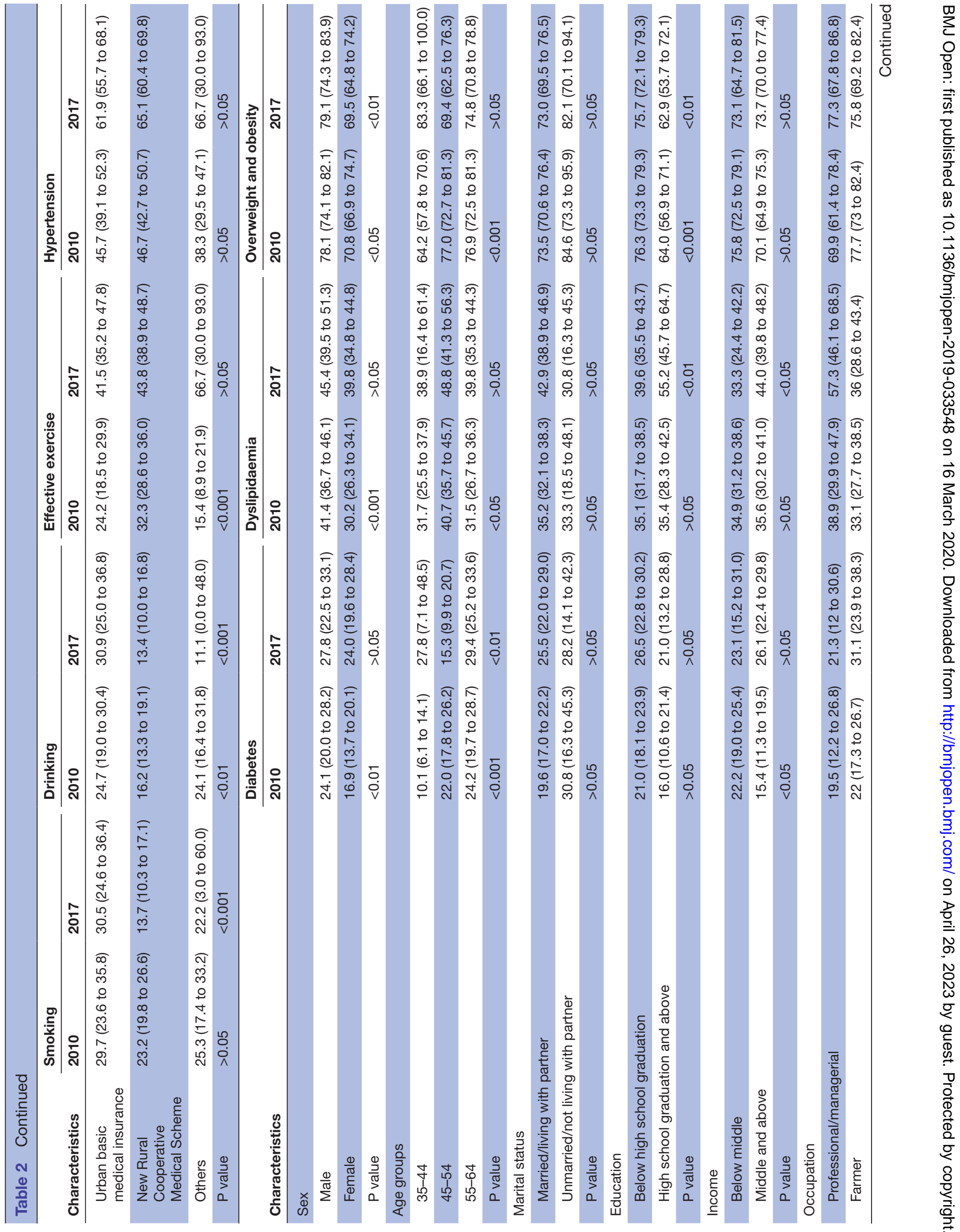




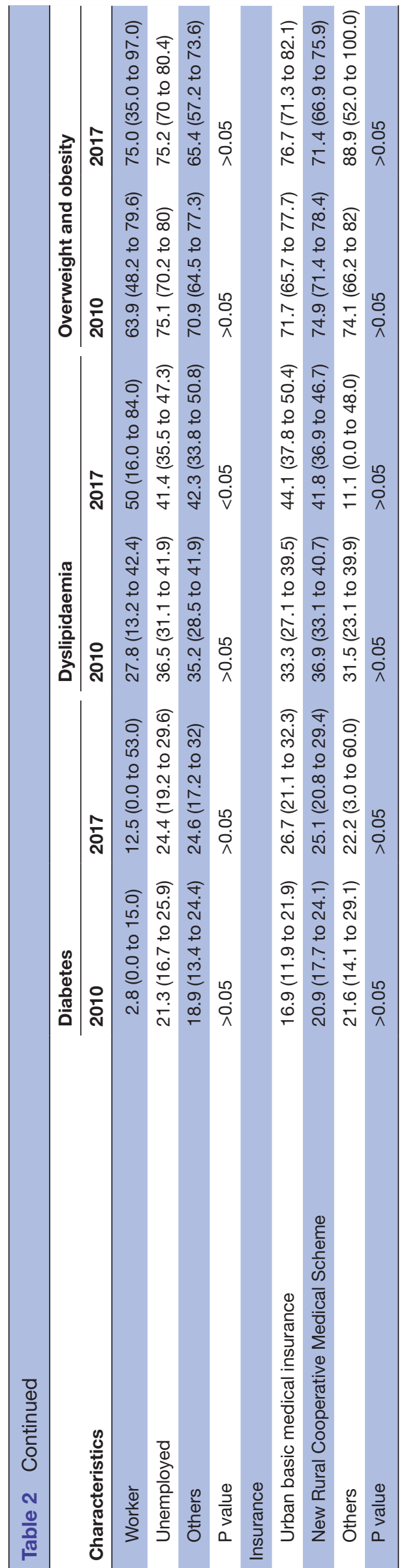

Changes of CVD risk factors from 2010 to 2017

Table 3 shows that SBP, DBP, CBP, HDL-C, PBF and VFI all rose after 7 years when only considering time. Multiple linear regression suggested that after adjusting for demographic and family history factors, DBP was elevated by a mean of $3.55 \mathrm{~mm} \mathrm{Hg}$, CBP increased by a mean of $4.39 \mathrm{~mm}$ $\mathrm{Hg}$, while TC decreased by a mean of $0.29 \mathrm{mmol} / \mathrm{L}$.

Table 4 demonstrates that when compared with 2010, the 2017 prevalence of hypertension $(\mathrm{PRR}=1.41)$, diabetes (PRR=1.36), dyslipidaemia (PRR=1.19) and effective exercise (PRR=1.57) increased markedly when only time was considered. Log-binomial models results indicated that after adjusting for demographic factors, lifestyles and family histories, the PRR of hypertension between 2017 and 2010 was $1.25(\mathrm{p}<0.05)$, while other risk factors were not significantly changed.

\section{Overall risk assessment of ASCVD}

In 2017, the 10-year risk of ASCVD was increased in $29.8 \%$ of individuals and decreased in $6.1 \%$ of individuals. In addition, $20.6 \%$ of the original low-risk people, $36.3 \%$ of the original moderate-risk participants and $11.5 \%$ of the original high-risk individuals went up to high or extremely high-risk level. In contrast, $20.4 \%$ of the original moderate-risk people and $8.4 \%$ of the original high-risk participants went down to lower levels. For those with an original moderate or high risk, the proportion of people with an increased risk was higher than that of people with a reduced risk (see table 5).

\section{Drop-out effects}

Table 6 shows the analysis of the baseline characteristics of the valid $(\mathrm{n}=640)$ and invalid samples $(\mathrm{n}=302)$ in 2017. There were no statistical differences in the distribution of socioeconomic characteristics, lifestyles or disease characteristics between the two samples $(p>0.05)$, indicating that 302 participants not included in final analysis had a similar CVD risk patterns as those who were in the follow-up study.

\section{DISCUSSION}

This is a rare longitudinal study which uses reliable clinical data to explore the changes in cardiovascular health risks of in situ urbanised rural residents. The research provides valuable evidence regarding changes in CVD risk factors over 7 years in an understudied population from the aspects of clinical indicators, prevalence rates and overall risk. Our study demonstrated that in addition to changes in living conditions and ageing, income levels improved significantly over past 7 years. Results revealed that serum biochemicals and physical examination indexes of research population had markedly changed. This is mainly reflected in increases of BP (DBP, CBP) and improved TC. The increased overall risks of CVD, especially the prevalence of hypertension, were major health issues for this population. 
Table 3 Changes of serum biochemicals and physical examination indexes during 7 years

\begin{tabular}{|c|c|c|c|c|}
\hline \multirow[b]{2}{*}{ Indexes } & \multicolumn{2}{|l|}{ Mean } & \multirow[b]{2}{*}{ Differences $(95 \% \mathrm{Cl})$} & \multirow[b]{2}{*}{ Adjusted differences $(95 \% \mathrm{Cl})$} \\
\hline & $2010(n=640)$ & $2017(n=640)$ & & \\
\hline SBP, $\mathrm{mm} \mathrm{Hg}$ & 132.16 & 134.72 & $2.55(0.68 \text { to } 4.42)^{*}$ & $1.46(-0.90$ to 3.82$)$ \\
\hline $\mathrm{CBP}, \mathrm{mm} \mathrm{Hg}$ & 121.86 & 127.66 & $5.80(4.04 \text { to } 7.55)^{*}$ & $4.39(2.17 \text { to } 6.61)^{*}$ \\
\hline $\mathrm{FPG}, \mathrm{mmol} / \mathrm{L}$ & 6.28 & 6.19 & $-0.09(-0.29$ to 0.11$)$ & $-0.16(-0.41$ to 0.10$)$ \\
\hline LDL-C, mmol/L & 3.12 & 3.08 & $-0.04(-0.14$ to 0.06$)$ & $-0.13(-0.26$ to 0.01$)$ \\
\hline $\mathrm{HDL}-\mathrm{C}, \mathrm{mmol} / \mathrm{L}$ & 1.33 & 1.37 & $0.05(0.01 \text { to } 0.08)^{\star}$ & $0.03(-0.01$ to 0.07$)$ \\
\hline $\mathrm{BMI}, \mathrm{kg} / \mathrm{m}^{2}$ & 26.17 & 26.04 & $-0.13(-0.52$ to 2.56$)$ & $-0.28(-0.78$ to 0.23$)$ \\
\hline PBF, \% & 31.67 & 32.47 & $0.80(0.16 \text { to } 1.43)^{*}$ & $-0.01(-0.61$ to 0.61$)$ \\
\hline
\end{tabular}

Models were adjusted for time $(2017=1,2010=0)$, sex (male=1, female=0), age groups $(35-44=1,45-54=2,55-64=3)$, marital status (married/living with partner $=1$, unmarried/not living with partner=0), education ( $\geq$ high school graduation=1, $<$ high school graduation=0), income (middle and above=1, below middle=0), professional/managerial (yes=1, no=0), farmer (yes=1, no=0), worker $($ yes $=1$, no=0), unemployed (yes=1, no=0), Urban Basic Medical Insurance (yes=1, no=0), New Rural Cooperative Medical Scheme (yes=1, no=0), smoking (yes $=1, \mathrm{no}=0$ ), drinking (yes $=1, \mathrm{no}=0$ ), effective exercise (yes=1, no=0), overweight and obesity (yes $=1$, no=0), family history of hypertension (yes=1, no=0), family history of dyslipidaemia (yes=1, no=0), family history of diabetes $(Y e s=1, \mathrm{No}=0$ ).

*Differences between 2017 and 2010, significant at $p<0.05$, the reference group was baseline in 2010.

$\mathrm{BMI}$, body mass index; CBP, central blood pressure; DBP, diastolic blood pressure; FPG, fasting plasma glucose; HDL-C, high-density lipoprotein cholesterol; LDL-C, low-density lipoprotein cholesterol; PBF, percentage body fat; SBP, systolic blood pressure; TC, total cholesterol; TG, triglyceride; VFI, visceral fat index.

As a part of multicentre research, the survey followed the unified implementation plan for data collection and quality control, ensuring the data's reliability. Related studies ${ }^{25-27}$ have shown that standardised prevalence rates of hypertension, hyperglycaemia, obesity and high TC among the people of Hongbo community in Chaoyang District were in first or second place when compared with other subgroups in the multicentre study, indicating a high risk of CVD for this population. This is also supported by comparisons with other national surveys in China. ${ }^{28-31}$

Another finding is that compared with an investigation of 9-year changes of metabolic syndrome in a newly formed urban community in Shanghai, same upward trends in prevalence of hypertension and diabetes were observed and the increase of hypertension in our study is higher than that in Shanghai. However, there were also obvious differences in trends of FPG, BP and TG between the two

Table 4 Changes of prevalence of main risk factors during 7 years

\begin{tabular}{|c|c|c|c|c|}
\hline \multirow[b]{2}{*}{ Outcomes } & \multicolumn{2}{|l|}{ Prevalence } & \multirow[b]{2}{*}{ PRR $(95 \% \mathrm{Cl})$} & \multirow[b]{2}{*}{ Adjusted PRR $(95 \% \mathrm{Cl}$} \\
\hline & $2010(n=640)$ & $2017(n=640)$ & & \\
\hline Smoking, \% & 23.60 & 20.00 & 0.85 (0.69 to 1.04$)$ & $0.92(0.73$ to 1.16$)$ \\
\hline Effective exercise, \% & 27.50 & 43.30 & $1.57(1.35 \text { to } 1.84)^{\star}$ & $0.98(0.83$ to 1.15$)$ \\
\hline Hypertension, \% & 45.30 & 63.90 & $1.41(1.27 \text { to } 1.56)^{\star}$ & $1.25(1.10 \text { to } 1.42)^{\star}$ \\
\hline Dyslipidaemia, \% & 35.50 & 42.20 & $1.19(1.04 \text { to } 1.37)^{\star}$ & 1.11 (0.93 to 1.32$)$ \\
\hline Overweight and obesity, \% & 74.40 & 73.60 & 0.99 (0.93 to 1.06$)$ & 0.95 (0.88 to 1.03$)$ \\
\hline
\end{tabular}

Models were adjusted for time $(2017=1,2010=0)$, sex (male=1, female=0), age groups $(35-44=1$, 45-54=2, 55-64=3), marital status (married/living with partner=1, unmarried/not living with partner=0), education ( $\geq$ high school graduation=1, $<$ high school graduation=0), income (middle and above=1, below middle=0), professional/managerial (yes=1, no=0), farmer (yes=1, no=0), worker $($ yes $=1$, no=0), unemployed (yes=1, no=0), Urban Basic Medical Insurance (yes=1, no=0), New Rural Cooperative Medical Scheme (yes=1, no=0), smoking (yes $=1, \mathrm{no}=0$ ), drinking (yes $=1$, no=0), effective exercise (yes=1, no=0), overweight and obesity (yes=1, no=0), family history of hypertension (yes=1, no=0), family history of dyslipidaemia (yes=1, no=0), family history of diabetes $(\mathrm{Yes}=1, \mathrm{No}=0$ ).

*PRR between 2017 and 2010 significant at $p<0.05$, the reference group was baseline in 2010.

PRR, prevalence rate ratio. 
Table 5 The changes in the risk level of ASCVD from 2010 to 2017

Risk level in 2017

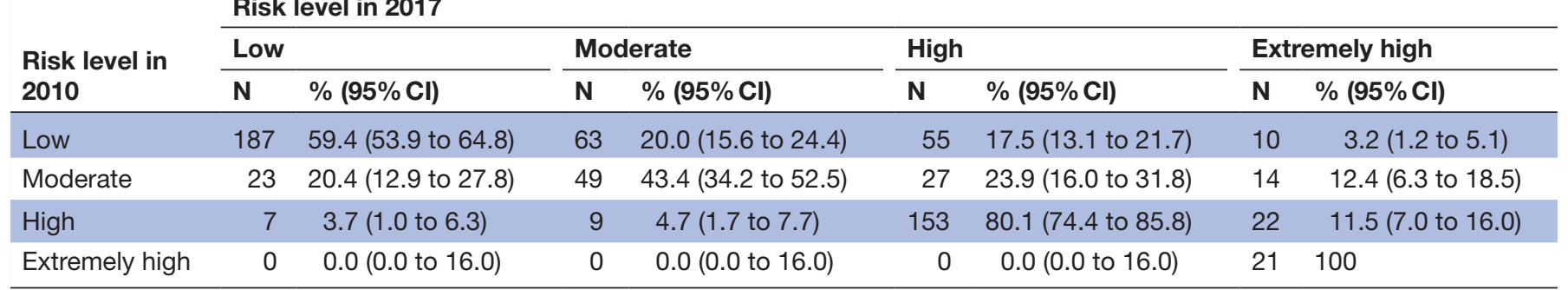

ASCVD, atherosclerotic cardiovascular disease.

studies. The regional differences of major cardiovascular risk factors in China had been confirmed by numerous researchers, which indicated that diversity was closely related to the natural geographical environment, social and economic development level, lifestyle choices (such as dietary habits) and the national cultural characteristics of different groups. ${ }^{27-29} 3233$ Our findings also show that although FPG did not demonstrate a significant change, the prevalence of diabetes dramatically increased. This suggests that the increased prevalence is mainly due to the increased number of self-reported patients and their higher treatment rates, which is closely related to their greater ability to access high-quality health services in recent years. $^{34}$

Moreover, we found that CBP increased more than peripheral BP. There was evidence that the heart, kidneys and cerebral arteries are primarily related to aortic pressure rather than brachial arteries. This means that CBP is more closely related to cardiovascular risk than brachial artery pressure. ${ }^{35}$ CBP may be a more direct predictor of cardiovascular events and target-organ damage than brachial BP, which tends to independently predict CVD. ${ }^{3637}$ Strong Heart research has also suggested that CBP is a better predictor of future cardiovascular events in healthy individuals than brachial artery pressure. ${ }^{38} \mathrm{~A}$ follow-up study of 9.5 years demonstrated that people with elevated brachial artery BP and low CBP did not have a high cardiovascular risk, known as 'pseudohypertension'. ${ }^{39}$ Therefore, the value of applying CBP for identifying true and false hypertension in young people has been included in the European hypertension guidelines of 2013. ${ }^{4041}$ Authors of future Chinese hypertension guidelines should also pay attention to CBP. Based on the evidence above, we believe that the risk of CVD for in situ urbanised residents rose faster than expected.

There is also a bright side to our findings. We observed a favourable trend in effective exercise rate regardless of other factors. In fact, improvements to living conditions not only included housing conditions, but also surrounding supporting facilities. In the newly built community, fitness paths, health trails, gyms, health education activity rooms and other facilities provided a better supportive environment for residents to engage in regular physical activity. Findings from the Pan-European Study ${ }^{42}$ indicated that people who live close to a park are more likely to exercise than those who do not. Built environment characteristics are, therefore, important correlates of physical activity. ${ }^{43}$

Another finding was connected to the limitation ${ }^{44}$ of BMI in CVD risk assessment. Results showed that PBF and VFI may rise significantly without any change in BMI, which is an indirect measure of body fat mass and may not accurately reflect cardiovascular risks. However, PBF is a robust measure of obesity and a better indicator of cardiovascular risk factor than BMI for both adults and adolescents. ${ }^{45}$ VFI is also a precise, dependable predictor for evaluating visceral adiposity. ${ }^{47}$ Generally, visceral deposits of body fat are considered to play a vital role in CVD. Our research indicated that there was 'invisible obesity' in the research population.

Several limitations of our study should be considered. First, the true burden of risk factors in the research population may be underestimated, since inclusion of individuals in a cohort study might elevate the level of attention those people pay to health risks. Second, the issue of whether differences of changes and characteristics in our results come from in situ urbanisation has not been discussed. A suitable control group is needed for in-depth analysis. Third, as data from six participants with risk factors who died during the course of the study were not included in the analysis, this could mean that final results were underestimated. In addition, dietary factors were not included and information on lifestyles, family history and income was based on self-report, which may be subject to reporting bias and recall bias. Authors of future research should consider these factors. Finally, we acknowledge the limitations of cluster sampling and extrapolation.

In situ urbanisation is one of the most important forms of urbanisation in China. With the acceleration of urbanisation, the in situ urbanised population is increasing rapidly. Unlike our research, most studies about the changes of CVD risk factors focus on rural-to-urban migration and rarely on in situ urbanised rural residents. ${ }^{10-12}$ Our research puts more emphasis on objective indicators, meaning our results have increased objectivity and authenticity compared with research based on selfreports of health status. ${ }^{48-50}$ In addition, the naturalistic, longitudinal study design, the availability of data over an extended observation period as well as the rigorous 


\begin{tabular}{|c|c|c|c|}
\hline Characteristics & $\begin{array}{l}\text { Invalid } \\
\text { samples in } \\
2017(n=302)\end{array}$ & $\begin{array}{l}\text { Valid samples } \\
\text { in } 2017 \\
(n=640)\end{array}$ & $P$ value \\
\hline \multicolumn{4}{|c|}{ Demographic characteristics } \\
\hline Sex, n (\%) & & & $>0.05$ \\
\hline Male & $160(53.0)$ & $367(57.3)$ & \\
\hline Female & $142(47.0)$ & $273(42.7)$ & \\
\hline Age groups, n (\%) & & & $>0.05$ \\
\hline $35-44$ & $78(25.8)$ & $140(21.9)$ & \\
\hline $45-54$ & $107(35.4)$ & $262(40.9)$ & \\
\hline $55-64$ & $117(38.7)$ & $238(37.2)$ & \\
\hline Marital status, n (\%) & & & $>0.05$ \\
\hline $\begin{array}{l}\text { Married/living with } \\
\text { partner }\end{array}$ & $289(95.7)$ & 614 (95.9) & \\
\hline $\begin{array}{l}\text { Unmarried/not living } \\
\text { with partner }\end{array}$ & $13(4.3)$ & $26(4.1)$ & \\
\hline \multicolumn{4}{|l|}{ Education, n (\%) } \\
\hline $\begin{array}{l}\text { Below high school } \\
\text { graduation }\end{array}$ & $242(80.1)$ & $525(82.0)$ & $>0.05$ \\
\hline $\begin{array}{l}\text { High school } \\
\text { graduation and above }\end{array}$ & $60(19.9)$ & $115(18.0)$ & \\
\hline Income, n (\%) & & & $>0.05$ \\
\hline Below middle & $195(64.6)$ & $449(70.2)$ & \\
\hline Middle and above & $107(35.4)$ & $191(29.8)$ & \\
\hline Occupation, n (\%) & & & $>0.05$ \\
\hline $\begin{array}{l}\text { Professional/ } \\
\text { managerial }\end{array}$ & $35(11.6)$ & $78(12.2)$ & \\
\hline Farmer & $89(29.5)$ & 207 (32.3) & \\
\hline Worker & $11(3.6)$ & $25(3.9)$ & \\
\hline Unemployed & $93(30.8)$ & $208(32.5)$ & \\
\hline Others & $74(24.5)$ & $122(19.1)$ & \\
\hline Insurance, n (\%) & & & $>0.05$ \\
\hline $\begin{array}{l}\text { Urban Basic Medical } \\
\text { Insurance }\end{array}$ & $69(22.8)$ & $150(23.4)$ & \\
\hline $\begin{array}{l}\text { New Rural } \\
\text { Cooperative Medical } \\
\text { Scheme }\end{array}$ & $203(67.2)$ & $403(63.0)$ & \\
\hline Others & $30(10.0)$ & $87(13.6)$ & \\
\hline \multicolumn{4}{|l|}{ Lifestyles } \\
\hline Smoking, n (\%) & $85(28.1)$ & $151(23.6)$ & $>0.05$ \\
\hline Drinking, n (\%) & $69(22.8)$ & $115(18.0)$ & $>0.05$ \\
\hline $\begin{array}{l}\text { Effective exercise, } \\
\mathrm{n}(\%)\end{array}$ & $83(27.5)$ & $176(27.5)$ & $>0.05$ \\
\hline Hypertension, n (\%) & $134(44.4)$ & $290(45.3)$ & $>0.05$ \\
\hline Diabetes, n (\%) & $68(22.5)$ & $121(18.9)$ & $>0.05$ \\
\hline Dyslipidaemia, n (\%) & $104(34.4)$ & 227 (35.5) & $>0.05$ \\
\hline $\begin{array}{l}\text { Overweight and } \\
\text { obesity, } \mathrm{n}(\%)\end{array}$ & $221(73.2)$ & $476(74.4)$ & $>0.05$ \\
\hline \multicolumn{4}{|l|}{ Family history } \\
\hline $\begin{array}{l}\text { Family history of } \\
\text { hypertension, } \mathrm{n}(\%)\end{array}$ & $146(48.3)$ & $330(51.6)$ & $>0.05$ \\
\hline
\end{tabular}

Continued

\begin{tabular}{cccc} 
Table 6 Continued & & & \\
\hline & $\begin{array}{l}\text { Invalid } \\
\text { samples in } \\
\text { Characteristics }\end{array}$ & $\begin{array}{l}\text { Valid samples } \\
\text { in 2017 }\end{array}$ & \\
$\mathbf{( n = 6 4 0 )}$ & P value \\
\hline $\begin{array}{l}\text { Family history of } \\
\text { dyslipidaemia, } \mathrm{n}(\%)\end{array}$ & $40(13.2)$ & $79(12.3)$ & $>0.05$ \\
$\begin{array}{l}\text { Family history of } \\
\text { diabetes, } \mathrm{n}(\%)\end{array}$ & $58(19.2)$ & $126(19.7)$ & $>0.05$ \\
\hline
\end{tabular}

statistical methods all enhance the dependability of our findings. Additionally, this research is also a part of the National Key Research and Development Program of China. In the future, we will conduct research to assess the influence of social determinants on cardiovascular risk factors. Changes in CVD risk are easily influenced by social determinants, such as socioeconomic status (SES) and residential environments. In different stages of urbanisation, CVD risks level could be distinct since risk response capacity varies among urbanised residents with different SES. In addition, whether residential environments characterised by increased socioeconomic resources, access to healthy foods and more resources for physical activity have a measurable effect on CVD and the density of CVD risk factors is also worth exploring.

\section{CONCLUSIONS}

Based on a prospective study design, we found that CVD risk was markedly augmented for in situ urbanised rural residents aged 35-64 years in the Chaoyang District of Beijing. Risk factors for CVD are becoming more prevalent. Between 2010 and 2017, BP levels and the increase of hypertension among this population should be further explored. Further steps for CVD risk factor control among this population should be emphasised. Additionally, macro social determinants which may predict differences in CVD risk should be addressed.

Acknowledgements The authors thank all the dedicated fieldworkers who took part in the surveys, all participants who facilitated the survey implementation and the editorial assistance from EditSprings.

Contributors ZL was first author and drafted the manuscript. XH obtained funding. HY designed the study and collected the data. ZL and SY were involved in data cleaning and analyzing. JL and HY contributed to the critical revision of the manuscript for important intellectual content and approved the final version of the manuscript. All authors have read and approved the final manuscript. Administrative, technical and logistic support was provided by all authors.

Funding This study was supported by the National Key Research and Development Program of China (2016YFC0900603) and the Chinese National Special Fund for Health-Scientific Research in the Public Interest (200902001).

Competing interests None declared.

Patient consent for publication Not required.

Ethics approval Ethics Review Boards of Fuwai hospital and Chaoyang District Center for Disease Control and Prevention approved this study (CYCDPCIRB-20090630-1).

Provenance and peer review Not commissioned; externally peer reviewed. Data availability statement No data are available. 
Open access This is an open access article distributed in accordance with the Creative Commons Attribution Non Commercial (CC BY-NC 4.0) license, which permits others to distribute, remix, adapt, build upon this work non-commercially, and license their derivative works on different terms, provided the original work is properly cited, appropriate credit is given, any changes made indicated, and the use is non-commercial. See: http://creativecommons.org/licenses/by-nc/4.0/.

ORCID iD

Zhe Li http://orcid.org/0000-0001-9344-6180

\section{REFERENCES}

1 China National Bureau of Statistics. Statistical Communique of China on 2018 national economic and social development. Available: http://www.stats.gov.cn/tjsj/zxfb/201902/t20190228_1651265.html [Accessed 7 Jun 2019].

2 Development Research Center of the State Council. Promoting Effient, comprehensive and sustainable urbanization in China, 2014. Available: http://www.worldbank.org/content/dam/Worldbank/ document/EAP/China/urban-china-overview-cn.pdf [Accessed 3 Sep 2018].

3 Li X, Wang C, Zhang G, et al. Urbanisation and human health in China: spatial features and a systemic perspective. Environ Sci Pollut Res Int 2012:19:1375-84.

4 Gong P, Liang S, Carlton EJ, et al. Urbanisation and health in China. Lancet 2012;379:843-52.

5 Chan KW. China, internal migration. In: Ness I, Bellwood P, eds. The encyclopedia of global migration. Blackwell Publishing, 2013: 67-72.

6 Bundy JD, He J. Hypertension and related cardiovascular disease burden in China. Ann Glob Health 2016;82:227-33.

7 Hong $\mathrm{X}, \mathrm{Ye} \mathrm{Q}, \mathrm{He} \mathrm{J}$, et al. Prevalence and clustering of cardiovascular risk factors: a cross-sectional survey among Nanjing adults in China. BMJ Open 2018;8:e020530.

8 Hanefeld J. Globalization and health. Maidenhead, UK: Open University Press, 2015: 3-10.

9 Goryakin Y, Rocco L, Suhrcke M. The contribution of urbanization to non-communicable diseases: evidence from 173 countries from 1980 to 2008. Econ Hum Biol 2017;26:151-63.

10 Chen J. Chronic conditions and receipt of treatment among urbanized rural residents in China. Biomed Res Int 2013;2013:1-8.

11 Jiang B, Li B, Wang Y, et al. The nine-year changes of the incidence and characteristics of metabolic syndrome in China: longitudinal comparisons of the two cross-sectional surveys in a newly formed urban community. Cardiovasc Diabetol 2016;15:84.

12 Han B, Chen Y, Cheng J, et al. Comparison of the prevalence of metabolic disease between two types of urbanization in China. Front Endocrinol 2018;9:665.

13 Chinese Government Network. Government work report in Beijing, 2009. Available: http://www.gov.cn/test/2009-02/13/content_ 1230040_2.htm

14 Lao XQ, Ma WJ, Sobko T, et al. Overall obesity is leveling-off while abdominal obesity continues to rise in a Chinese population experiencing rapid economic development: analysis of serial crosssectional health survey data 2002-2010. Int J Obes 2015;39:288-94.

15 Yiengprugsawan V, Caldwell BK, Lim LL-Y, et al. Lifecourse urbanization, social demography, and health outcomes among a national cohort of 71,516 adults in Thailand. Int $J$ Popul Res 2011;2011:1-9

16 Hao G, Wang Z, Zhang L, et al. Prevalence of microalbuminuria among middle-aged population of China: a multiple center cardiovascular epidemiological study. Angiology 2015;66:49-56.

17 Plan and operation of the third National health and nutrition examination survey, 1988-94. series 1: programs and collection procedures. Vital Health Stat 1 1994;1:1-407.

18 Burt VL, Whelton P, Roccella EJ, et al. Prevalence of hypertension in the US adult population. results from the third National health and nutrition examination survey, 1988-1991. Hypertension 1995;25:305-13.

19 Ott C, Haetinger S, Schneider MP, et al. Comparison of two noninvasive devices for measurement of central systolic blood pressure with invasive measurement during cardiac catheterization. $J$ Clin Hypertens 2012;14:575-9.

20 Garcia-Ortiz L, Recio-Rodríguez JI, Canales-Reina JJ, et al. Comparison of two measuring instruments, B-pro and SphygmoCor system as reference, to evaluate central systolic blood pressure and radial augmentation index. Hypertens Res 2012;35:617-23.

21 Bei-Fan Z. The cooperative meta-analysis group of working group on obesity in China. Predictive values of body mass index and waist circumference for risk factors of certain related diseases in Chinese adults: study on optimal cut-off points of body mass index and waist circumference in Chinese adults. Chin J Epidemiol 2002;11:S685-93.

22 Lee J, Chia KS. Estimation of prevalence rate ratios for cross sectional data: an example in occupational epidemiology. $\mathrm{Br} \mathrm{J}$ Ind Med 1993;50:861-2.

23 Axelson O, Fredriksson M, Ekberg K. Use of the prevalence ratio $\mathrm{V}$ the prevalence odds ratio as a measure of risk in cross sectional studies. Occup Environ Med 1994;51:574.

24 Chinese cardiovascular disease prevention guide. Chin J Cardiol 2018;46:10-25.

25 Wang Z, Zeng X, Chen Z, et al. Association of visceral and total body fat with hypertension and prehypertension in a middle-aged Chinese population. $J$ Hypertens 2015;33:1555-62.

26 Hao G, Wang Z, Zhang L, et al. Relationship between alcohol consumption and serum lipid profiles among middle-aged population in China: a Multiple-Center cardiovascular epidemiological study. Angiology 2015;66:753-8.

27 Zhang L, Wang Z, Chen Z, et al. Secular trends of major cardiovascular risk factors in middle -aged Chinese during the period of 1982 to 2010. J Med Res 2019:48:39-44.

28 Wang Z, Chen Z, Zhang L, et al. Status of hypertension in China: results from the China hypertension survey, 2012-2015. Circulation 2018;137:2344-56.

29 Li Y, Yang L, Wang L, et al. Burden of hypertension in China: a nationally representative survey of 174,621 adults. Int $J$ Cardiol 2017;:227:516-23.

$30 \mathrm{He} \mathrm{J}$, Gu D, Reynolds K, et al. Serum total and lipoprotein cholesterol levels and awareness, treatment, and control of hypercholesterolemia in China. Circulation 2004;110:405-11.

31 Pan L, Yang Z, Wu Y, et al. The prevalence, awareness, treatment and control of dyslipidemia among adults in China. Atherosclerosis 2016;248:2-9.

32 Zhang M, Deng Q, Wang L, et al. Prevalence of dyslipidemia and achievement of low-density lipoprotein cholesterol targets in Chinese adults: a nationally representative survey of 163,641 adults. Int $J$ Cardiol 2018;260:196-203.

33 Zhou M, Astell-Burt T, Bi Y, et al. Geographical variation in diabetes prevalence and detection in China: multilevel spatial analysis of 98,058 adults. Diabetes Care 2015;38:72-81.

34 Bo ZN GAO, Xiao-hui ea REN. Impact of urbanization on the residents' health service needs and utilization based on the urban and Rura integration development. J Sichuan Univ 2013;44:255-60.

35 Olafiranye O, Ibrahim M, Kamran $\mathrm{H}$, et al. Narrowed Aortoseptal angle is related to increased central blood pressure and aortic pressure wave reflection. Cardiorenal Med 2012;2:177-83.

36 Ben-Shlomo Y, Spears M, Boustred C, et al. Aortic pulse wave velocity improves cardiovascular event prediction: an individual participant meta-analysis of prospective observational data from 17,635 subjects. J Am Coll Cardiol 2014;63:636-46.

37 Safar ME, Jankowski P. Central blood pressure and hypertension: role in cardiovascular risk assessment. Clin Sci 2009;116:273-82.

38 Roman MJ, Devereux RB, Kizer JR, et al. Central pressure more strongly relates to vascular disease and outcome than does brachial pressure: the strong heart study. Hypertension 2007;50:197-203.

39 Saladini F, Santonastaso M, Mos L, et al. Isolated systolic hypertension of young-to-middle-age individuals implies a relatively low risk of developing hypertension needing treatment when central blood pressure is low. J Hypertens 2011;29:1-9.

40 Radchenko GD, Torbas OO, Sirenko YM. Predictors of high central blood pressure in young with isolated systolic hypertension. Vasc Health Risk Manag 2016;12:321-8.

41 Mancia G, Fagard R, Narkiewicz K, et al. 2013 ESH/ESC guidelines for the management of arterial hypertension: the task force for the management of arterial hypertension of the European Society of hypertension (ESH) and of the European Society of cardiology (ESC). Eur Heart $J$ 2013;34:2159-219.

42 Bonnefoy XR, Braubach M, Moissonnier B, et al. Housing and health in Europe: preliminary results of a pan-European study. Am J Public Health 2003;93:1559-63.

43 Eichinger M, Titze S, Haditsch B, et al. How are physical activity behaviors and cardiovascular risk factors associated with characteristics of the built and social residential environment? PLOS One 2015;10:e0126010.

44 Palaniappan LP, Wong EC, Shin JJ, et al. Asian Americans have greater prevalence of metabolic syndrome despite lower body mass index. Int J Obes 2011;35:393-400.

45 Zeng Q, Dong S-Y, Sun X-N, et al. Percent body fat is a better predictor of cardiovascular risk factors than body mass index. Braz $\mathrm{J}$ Med Biol Res 2012;45:591-600.

46 Trang LT, Trung NN, Chu D-T, et al. Percentage body fat is as a good indicator for determining adolescents who are overweight or obese: a 
cross-sectional study in Vietnam. Osong Public Health Res Perspect 2019;10:108-14.

47 Amato MC, Pizzolanti G, Torregrossa V, et al. Visceral adiposity index (VAI) is predictive of an altered adipokine profile in patients with type 2 diabetes. PLoS One 2014;9:e91969.

48 Liang Y, Lu W, Wu W. Are social security policies for Chinese landless farmers really effective on health in the process of Chinese rapid urbanization? A study on the effect of social security policies for
Chinese landless farmers on their health-related quality of life. Int $J$ Equity Health 2014:13:5.

49 Liu Y, Huang B, Wang R, et al. Exploring the association between urbanisation and self-rated health of older adults in China: evidence from a national population sample survey. BMJ Open 2019;9:e029176.

50 Hwang S-S, Cao Y, Xi J. The Short-term impact of involuntary migration in China's three gorges: a prospective study. Soc Indic Res 2011;101:73-92 